\title{
Metabolic Responses of Women to Exercise Attributable to Long Term Use of a Manual Wheelchair
}

\author{
Maria Tahamont, Ph.D., ${ }^{1}$ R. G. Knowlton, Ph.D., ${ }^{2}$ M. N. Sawka, Ph.D., ${ }^{3}$ \\ D. S. Miles, Ph.D. ${ }^{4}$ \\ ${ }^{1}$ Department of Physiology, Fefferson Medical College, Philadelphia, Pennyslvania; \\ ${ }^{2}$ Department of Physical Education, Southern Illinois University at Carbondale, \\ Carbondale, Illinois; ${ }^{3}$ U.S. Army Research Institute of Environmental Medicine, \\ Natick, Massachusetts; ${ }^{4}$ Department of Physiology, Wright State School of \\ Medicine, Dayton, Ohio.
}

\section{Summary}

The purpose of this study was to determine the effects of long term use of a manual wheelchair by wheelchair-confined women $(\bar{X}=14.6$ years $)$ on physiological responses to wheelchair ergometry. Six experimental subjects were compared to six able bodied women during maximal exercise as well as submaximal wheelchair ergometry at 50 and $80^{\circ}{ }_{0}$ of peak $\dot{V} \mathrm{O}_{2}$. The wheelchair dependent women achieved higher power outputs, greater efficiency at the higher submaximal workload, less metabolic acidosis during submaximal exercise as well as less ventilatory stress. There was no significant difference in peak $\mathrm{VO}_{2}$ between the two groups of women. Because these were not athletically trained women, it was concluded that the long term use of a manual wheelchair leads to physiological adaptations favourable to the daily requirements of wheelchair locomotion.

\section{Introduction}

Numerous studies (Glaser et al., 1980; Sawka et al., 1980; Glaser et al., 1981; Coutts et al., 1983; Coutts, 1984) have clearly demonstrated that wheelchair exercise can be a stressful form of physical activity. Physiological adaptations to wheelchair ergometry have been shown to occur with short term training (Gass \& Camp, 1979; Chawla et al., 1980; Gass et al., 1980; Glaser et al., 1981; Miles et al., 1982) however, no studies exist to show the extent to which long term use of a self-propelled wheelchair affects the physiological response required by this form of locomotion. Because studies using wheelchair dependent women are rare, this information would be important because of the known physiological differences in strength (Singh \& Karpovich, 1968; Hoffman et al., 1979) hemoglobin concentration (Guyton, 1976) and pulmonary function (Slonim \& Hamilton, 1976) that exist between men and women.

Therefore, the purpose of this study was to determine the influence of long term manual wheelchair locomotion on the physiological responses of women 
during controlled exercise. To achieve this, oxygen consumption and acid-base balance were compared between wheelchair dependent women (WD) and able bodied $(\mathrm{AB})$ control subjects during wheelchair ergometry.

\section{Subjects and methods}

Twelve women (six wheelchair dependent, WD; and six able bodied, AB) were studied. The general characteristics including grip strength, the disability level, as well as the period of wheelchair confinement of the WD subjects have been presented in Table 1. All participants completed a medical history, were free from any known pulmonary or cardiovascular diseases and signed an informed consent statement prior to participation in this investigation. None of the women were athletes or engaged in systematic training. The protocol and procedures were approved by the local committee assigned to review experimentation involving the use of human subjects.

Table 1 General characteristics of all subjects

\begin{tabular}{|c|c|c|c|c|c|}
\hline \multirow[b]{2}{*}{ Subject } & \multirow[b]{2}{*}{ Age $(Y r)$} & \multirow[b]{2}{*}{ Disability } & \multirow[b]{2}{*}{ Years in Wheelchair } & \multicolumn{2}{|c|}{ Grip Strength } \\
\hline & & & & $\mathrm{R}(\mathrm{kg})$ & $\mathrm{L}(\mathrm{kg})$ \\
\hline & & Experimental Subjects (WD) & & & \\
\hline 1 & 23 & L3, 4 Trauma & 21 & 43 & 40 \\
\hline 2 & 24 & T10 Trauma & 3 & 53 & 51 \\
\hline 3 & 35 & L11 Trauma & 18 & 29 & 26 \\
\hline 4 & 31 & -Disease & 31 & 31 & 35 \\
\hline 5 & 23 & -Disease & 8 & 40 & 40 \\
\hline 6 & 28 & T11, 12 Trauma & 7 & 40 & 41 \\
\hline Mean & $27 \cdot 30$ & & $14 \cdot 60$ & $39 \cdot 3$ & $38 \cdot 8$ \\
\hline \multirow[t]{2}{*}{ SE } & $2 \cdot 60$ & & $4 \cdot 00$ & $3 \cdot 3$ & $4 \cdot 3$ \\
\hline & & Controls (AB Subjects) & & & \\
\hline Mean & $24 \cdot 5$ & & & $38 \cdot 6$ & $36 \cdot 3$ \\
\hline SE & $1 \cdot 7$ & & & $2 \cdot 0$ & $3 \cdot 3$ \\
\hline
\end{tabular}

All testing was conducted in an air-conditioned laboratory with a room temperature of approximately $23^{\circ} \mathrm{C}$ and relative humidity of approximately $50^{\circ}{ }_{0}$. A wheelchair ergometer designed after one reported to stimulate the physiological requirements of manual wheelchair operation (Glaser et al., 1979) was used in this study. For the maximal test the subjects were asked to perform a discontinuous protocol with the initial workload at 6.2 watts with an increment of 5.9 watts for successive stages. Each stage was five minutes in duration followed by a ten minute rest period which was extended if necessary to bring the heart rate below $100 \mathrm{bpm}$. This test continued until an exercise stage proved too difficult as judged by an inability of the subject to maintain the required work rate. The Rated Perceived Exertion (RPE) was determined at the conclusion by use of the Borg Scale (Borg, 1975).

Subsequent to the maximal test and after at least a 1 week delay the submaximal tests were performed. On separate days and in a random sequence the subjects worked both at $50^{\circ}{ }_{0}$ and $80^{\circ}$ o of the peak $\mathrm{VO}_{2}$ obtained during the discontinuous test. After 6 minutes of exercise metabolic data were collected 
as this was found to be an adequate period of time to reach a steady state response.

All respiratory and metabolic measurements were obtained by open circuit spirometry. Ventilation was measured with a dry gas meter (Parkinson-Cowans CD4) and recorded on an analog recorder (Beckman Type R Dynograph). The respiratory gases were continually analysed for percentages of carbon dioxide (Godart Capnograph) and oxygen (Beckman OM-11) with the mean gas percentages during the last minute of each stage used for the metabolic calculations (Consolazio et al., 1963). The electronic analysers were calibrated immediately before all gas collection periods by gas standards which had been previously analysed by chemical methods. The mechanical efficiency of wheelchair ergometry was calculated as suggested by Brattgard (1970). Arterialised finger capillary blood was taken immediately after exercise for the determination of $\mathrm{pH}$, carbon dioxide and bicarbonate concentrations by the equilibrium method of Astrup and the Siggaard-Anderson curve nomogram. Five minute post exercise samples of blood were obtained for blood lactate determinations by the enzymatic techniques of Gutman and Wahlefeld (1974). Heart rates were continuously monitored during all testing with an electrocardiogram using a bipolar lead placement (CM-5).

An unpaired t-test was used to test differences in physiological responses between groups. Differences were considered to be significant if they achieved $\mathrm{p}$ value of 0.05 .

\section{Results}

Table 2 contains summarised data from the maximal test. The WD subjects were able to achieve a higher maximal power output as well as to achieve their peak oxygen consumption at a lower pulmonary ventilation than was the case for the AB subjects. There were no significant differences between groups for peak oxygen uptake and maximal heart rate. The fact that at some point each subject failed to maintain a required power output was considered adequate evidence that the subjects were motivated to achieve a maximal test effort.

Table 2 Maximal values achieved during wheelchair ergometry

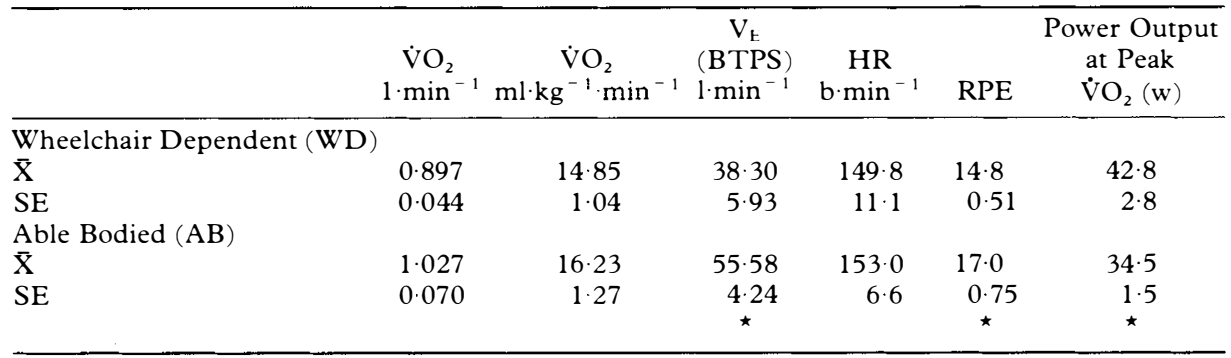

* Significant difference between groups $(\mathrm{p} \leqq 0.05)$.

Because of the group differences shown in the maximal test, workload settings for the $50^{\circ}{ }_{0}$ and $80^{\circ}{ }_{0}$ of peak $\mathrm{VO}_{2}$ were established separately for each subject. At the lower workload the WD and AB groups exercised at an average of 16 
Table 3 Respiratory responses to the two submaximal tests

\begin{tabular}{|c|c|c|c|c|c|c|c|c|}
\hline \multirow[b]{2}{*}{ ") of peak $\mathrm{VO}_{2}$} & \multicolumn{2}{|c|}{$\dot{\mathrm{VO}}_{2}\left(1 \cdot \mathrm{min}^{-1}\right)$} & \multicolumn{2}{|c|}{$\mathrm{VE}\left(1 \cdot \min ^{-1}\right)$} & \multicolumn{2}{|c|}{$\mathrm{HR}\left(\mathrm{B} \cdot \mathrm{min}^{-1}\right)$} & \multicolumn{2}{|c|}{$\mathrm{VE} \cdot \dot{\mathrm{VO}}_{2}{ }^{1}$} \\
\hline & 50 & 80 & $50 \star$ & $D^{80^{\star}}$ & 50 & 80 & $50^{\star}$ & $80^{\star}$ \\
\hline$\overline{\mathrm{X}}$ & 0.465 & 0.749 & $16 \cdot 3$ & 32.6 & $117 \cdot 0$ & $136 \cdot 0$ & $37 \cdot 5$ & 43.0 \\
\hline SE & 0.030 & 0.039 & 1.5 & $B^{3 \cdot 7}$ & $5 \cdot 4$ & $4 \cdot 9$ & $6 \cdot 3$ & $4 \cdot 7$ \\
\hline $\begin{array}{l}\bar{X} \\
S E\end{array}$ & $\begin{array}{l}0.561 \\
0.031\end{array}$ & $\begin{array}{l}0.814 \\
0.053\end{array}$ & $\begin{array}{r}24 \cdot 0 \\
3 \cdot 9\end{array}$ & $\begin{array}{r}40 \cdot 5 \\
3.3\end{array}$ & $\begin{array}{r}117 \cdot 0 \\
5 \cdot 1\end{array}$ & $\begin{array}{r}145 \cdot 0 \\
5 \cdot 1\end{array}$ & $\begin{array}{r}43 \cdot 9 \\
2 \cdot 7\end{array}$ & $\begin{array}{r}55 \cdot 0 \\
3 \cdot 7\end{array}$ \\
\hline
\end{tabular}

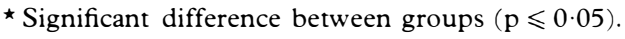

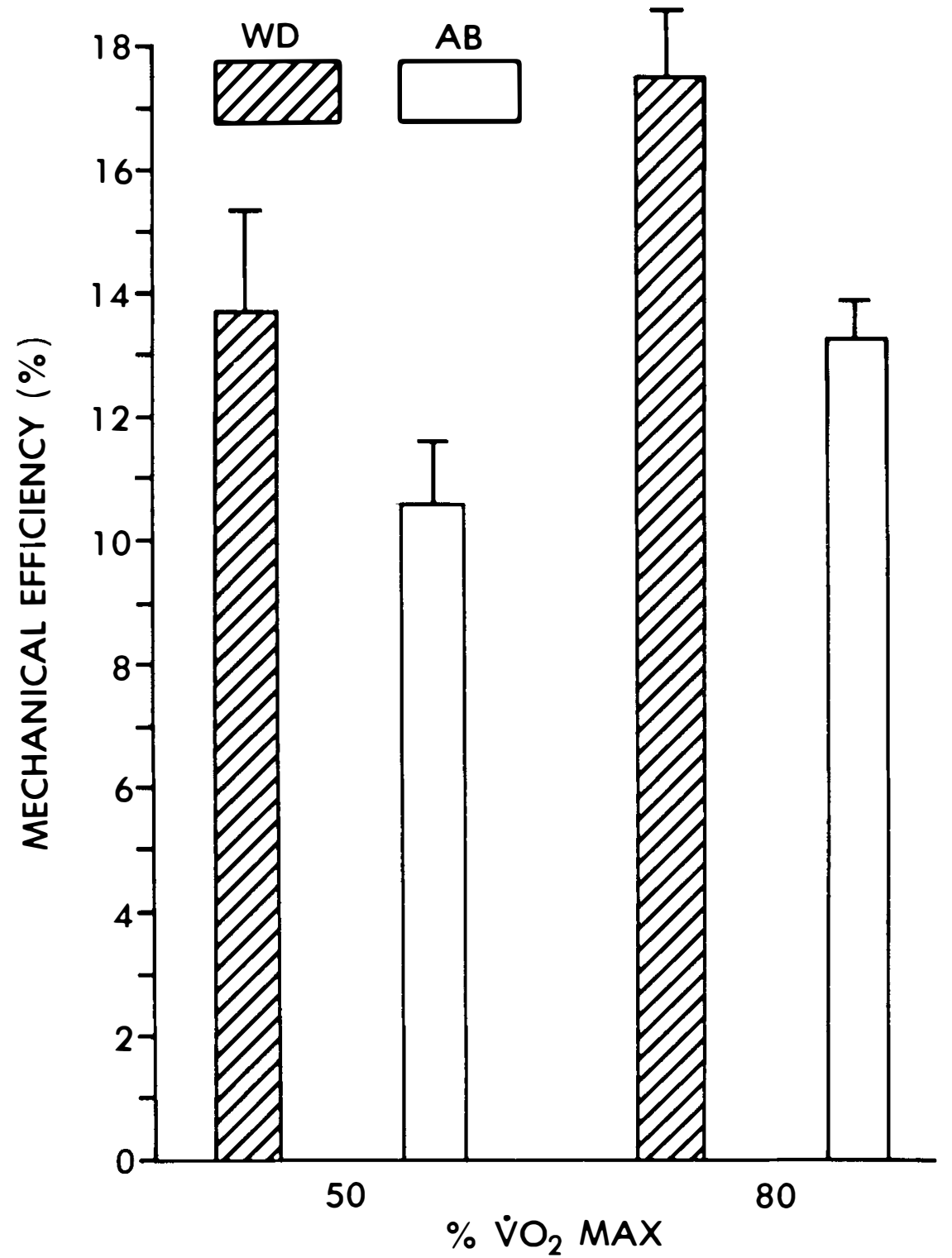

Figure 1. Mean efficiency \pm standard error at the two workloads. 
Table 4 Acid-base values after submaximal wheelchair ergometry

\begin{tabular}{|c|c|c|c|c|c|c|c|}
\hline \multirow{2}{*}{\multicolumn{2}{|c|}{$\mathrm{pH}$}} & \multicolumn{3}{|c|}{$50^{\prime \prime}$ " of peak $\dot{\mathrm{VO}}_{2}$} & \multicolumn{3}{|c|}{$80^{\prime \prime}$ " of peak $\mathrm{VO}_{2}$} \\
\hline & & $\begin{array}{c}\left(\mathrm{HCO}_{3}\right) \\
\mathrm{mEg}\end{array}$ & $\begin{array}{l}\mathrm{PCO}_{2} \\
\mathrm{mmHg}\end{array}$ & $\begin{array}{c}\text { Lactate } \\
\text { mmol }\end{array}$ & $\begin{array}{c}\left(\mathrm{HCO}_{3}\right) \\
\mathrm{mEg}\end{array}$ & $\begin{array}{c}\mathrm{PCO}_{2} \\
\mathrm{mmHg}\end{array}$ & $\begin{array}{c}\text { Lactate } \\
\text { mmol }\end{array}$ \\
\hline \multicolumn{8}{|c|}{ Experimental Group (WCD) } \\
\hline$\overline{\mathrm{X}}$ & $7 \cdot 410$ & $7 \cdot 380$ & $36 \cdot 4$ & 1.09 & $21 \cdot 1$ & $36 \cdot 6$ & 2.98 \\
\hline SE & 0.02 & $0 \cdot 18$ & $1 \cdot 5$ & $0 \cdot 30$ & 0.6 & 0.5 & 0.90 \\
\hline \multicolumn{8}{|c|}{ Control Group (AB) } \\
\hline$\overline{\mathrm{X}}$ & $7 \cdot 358$ & $7 \cdot 353$ & $36 \cdot 9$ & $3 \cdot 18$ & $19 \cdot 0$ & 37.0 & $5 \cdot 14$ \\
\hline SE & 0.02 & 0.55 & 0.5 & $0 \cdot 50$ & 0.8 & $1 \cdot 3$ & 0.50 \\
\hline
\end{tabular}

and 13.6 watts respectively with an increase to 31.3 and $27 \cdot 1$ for $80^{\circ}{ }_{0}$ of the peak $\mathrm{VO}_{2}$. Significant group differences occurred in the ventilatory equivalent, Table 3, at the lower submaximal work and lactate concentrations were significantly lower for WD in response to both submaximal tests. Figure 1 shows the mean mechanical efficiencies of the two groups at both submaximal exercises with the difference significant at the higher work requirement. Acid base variables, Table 4, presented a picture which described less metabolic acidosis for WD subjects during submaximal exercise both in terms of blood $\mathrm{pH}$ and plasma bicarbonate concentrations.

\section{Discussion}

A fairly recent literature review of wheelchair exercise (Dreisinger et al., 1982) reveals a near absence of studies of the physiological responses of paraplegic women to exercise. To our knowledge there are no previous studies that have attempted to compare untrained women accustomed to using a wheelchair with control subjects naive to this form of locomotion. The practicality of the present study rests with choice of submaximal workloads that reasonably apply to the requirements of everyday wheelchair locomotion. As the present experimental subjects were not athletic, it is reasonable to conclude that differences from the responses of control subjects could be attributed to the normal daily use of a wheelchair. No attempt has been made to determine the period of time required to establish group differences.

It was of interest to note that WD subjects were able to engage in a higher maximal power output than $\mathrm{AB}$ subjects while neither submaximal or maximal oxygen consumptions significantly varied between the two groups. There are three possible explanations for this observation. Nilsson et al. (1975) showed with a short term training program for paraplegic subjects that absolute work capacity increased to a greater extent than maximal oxygen uptake during arm cranking. This response may result from a more efficient distribution of blood flow established reflexively from the movement repetition. A second possibility is that strength differences between the groups favoured a greater maximal power output by the WD subjects. The use of a dynamic strength test which simulated the thrust movement required in the operation of a wheelchair would be more definitive but the greater total grip strength (Table 1) may have been a factor which favoured a greater power output by WD subjects. Finally, familiarity with the sensation of fatigue associated with wheelchair activity may have 
increased the tolerance of WD subjects for this stress imposed by heavy work. Rated Perceived Exertions (Borg, 1975) were 14.8 and 17.0 (Table 2; p < 0.05) respectively for WD and $\mathrm{AB}$ subjects at the termination of the maximal test which suggests that psychological perceptions associated with physical discomfort were less limiting for the WD subjects than for $A B$ subjects. Because of the similarity in maximum oxygen uptake it is likely that functional capacity of the cardiovascular system was not a discriminant factor with respect to maximal work capacity.

Brattgard et al. (1970) have suggested a means of calculating the mechanical efficiency of wheelchair exercise so that the extent to which total energy expenditure results in useful work can be expressed. In this regard, the most notable contrasts between groups, Figure 1, occurred at the higher of the two submaximal workloads. It should be pointed out that the $\mathrm{VE} / \mathrm{VO}_{2}$ for normal subjects are higher than those previously reported in normal subjects for arm ergometry (Magel et al., 1978; Glaser et al., 1979) which means that the able-bodied women may have been hyperventilating in part from inexperience with the form of exercise required by the test procedure. While this would lead to an overestimation of the effect of long term use of a wheelchair it is also reasonable to conclude that neuromuscular skill acquired by WD subjects would be of importance in proportion to the difficulty of the task. Empirically, it was noted that the means of stabilisation was achieved quite differently for the two groups studied. Clearly, the AB subjects relied on static contraction of the lower limbs to oppose the forward stroke of the arms the latter of which was assisted by forward flexion of the spine. This was most evident as the severity of work increased. In contrast, WD subjects were able to rely only on the upper body for stabilisation which was most likely achieved at a lower metabolic cost. As body stabilisation is not accounted for by the productive work that is measured, this aspect of manual wheelchair operation becomes important in the efficiency of its operation. These findings point to the need for an integrated biomechanicalphysiological study contrasting $\mathrm{WD}$ and $\mathrm{AB}$ subjects as much of the presently available literature on wheelchair exercise is inappropriately based on findings obtained from able-bodied subjects.

In view of what has been shown to exist for arm work (Davis et al., 1976; Tesch \& Lindberg, 1984) and the additional inefficiency of the movements required to propel a wheelchair, metabolic acidosis could be expected to occur at relatively low power outputs on the wheelchair ergometer. This was evidenced for both groups in the present study as even at the lower submaximal work plasma bicarbonate was lower than the value considered normal for resting conditions. Significantly higher lactate values were noted for AB subjects across both workloads indicating a greater general reliance upon anaerobic metabolism to provide energy for the submaximal work tasks. It is of interest that with the significantly greater ventilatory equivalent for oxygen in these subjects, Table 3 , there was not a difference in the partial pressure of carbon dioxide in arterialised blood, Table 4 , between groups. The possibility exists that a greater ventilatory drive occurred from neuromuscular stimulation and higher lactate values for $\mathrm{AB}$ subjects but without a proportionately increased alveolar gas exchange. As previously suggested, it is also possible that the reduced respiratory stress seen for WD subjects partially contributed to the greater mechanical efficiency seen for this group. 
In conclusion the present data show that long term adaptations to wheelchair locomotion can enhance submaximal metabolic responses to this form of exercise. Although the present data are from subjects with protracted wheelchair dependency, it is noteworthy that systematic training was not part of this study. It is reasonable to state that the present experimental subjects showed an accustomed response that has a direct influence on meeting the demands of daily locomotion.

\section{References}

BORG GAV 1975 Perceived exertion: A note on history and methods. Med Sci Sports 5:90-93.

Brattgard SO, Grimby G, Hook O 1970 Energy expenditure and heart rate driving a wheelchair ergometer. Scandinavian Journal of Rehabilitative Medicine 2:143-148.

Chawla JC, Bar C, CReber I, et al. 1980 Techniques for improving the strength and fitness of spinal injured patients. Paraplegia 17:185-189.

CoutTS KD 1984 Relation between oxygen uptake and power output during wheelchair ergometry in tetraplegics and paraplegics. Canadian Journal of Applied Sports Science 9:17-19.

Coutts KD, Rhodes CE, MCKenZIE DC 1983 Maximal exercise responses of tetraplegics and paraplegics. Journal of Applied Physiology 55:479-482.

DAvis JA, VodAK P, Wilmore JH, et al. 1976 Anaerobic threshold and maximal aerobic power for three modes of exercise. Journal of Applied Physiology 41:544-550.

Dreisinger DE, Londeree BR 1982 Wheelchair exercise: A review. Paraplegia 20:20-34.

Gass GC, CAMP EM 1979 Physiological characteristics of trained Australian paraplegic and tetraplegic subjects. Med Sci Sports 11:256-259.

Gass GC, Watson EM, Camp HJ, et al. 1980 The effect of training on high level spinal lesion patients. Scandinavian Journal of Rehabilitative Medicine 12:61-65.

Glaser RM, Foley DM, Laubach LL, et al. 1979 An exercise test to evaluate fitness for wheelchair activity. Paraplegia 16:341-349.

Glaser RM, GiNGER L, LAUBACH LL 1977 Validity and reliability of wheelchair ergometry. Physiologist 20:34.

Glaser RM, SAWKa MN, DURBIN RJ, et al. 1981 Exercise program for wheelchair activity. American Journal of Physical Medicine 60:67-75.

Glaser RM, SAWKA MN, LAUBACH LL 1979 Metabolic and cardiopulmonary responses to wheelchair and bicycle ergometry. Journal of Applied Physiology 1066-1070.

Glaser RM, Sawka MN, Laubach LL, et al. 1980 Metabolic and cardiopulmonary responses to wheelchair and arm crank ergometry. Journal of Applied Physiology 48:1060-1064.

Gutman I, WAHLEFELD AW 1974 L-lactate determinations with lactate dehydrogenase and NAD. In: Methods of enzymatic analyses. H. U. Gergmeyer, Editor, New York, Academic Press, 1464-1468.

Guyton AC 1976 Textbook of Medical Physiology, Edition 5, Philadelphia, W. B. Saunders.

Hoffman T, Stauffer RW, JaCkson AS 1979 Sex difference in strength. American Journal of Sports Medicine 7:265-267.

MAgel JR, MCARdLe WD, Toner M, et al. 1978 Metabolic and cardiovascular adjustment to arm training. Journal of Applied Physiology 45:75-79.

Miles DS, SAWKa MN, Wilde SW, et al. 1982 Pulmonary function changes in wheelchair athletes subsequent to exercise training. Ergonomics 25:239-246.

Nilsson S, Staff PH, Pruett EDR 1975 Physical work capacity and the effect of training on subjects with long standing paraplegia. Scandinavian Journal of Rehabilitative Medicine 7:51-56.

SAWka MN, Glaser RM, Wilde SW, et al. 1980 Metabolic and circulatory responses to wheelchair and arm crank exercise. Journal of Applied Physiology 49:784-788.

SingH M, KaRPOVICH PV 1968 Strength of forearm flexors and extensors in men and women. Journal of Applied Physiology 25:177-180.

SiggaARd-ANDERSON O, ENGel K, JoRgensen K, et al. 1960 A micro method for determination of $\mathrm{pH}$, carbon dioxide tension, base excess and standard bicarbonate in capillary blood. Scandinavian Journal of Clinical Laboratory Investigation 12:172-176.

Slonim NB, Hamilton LH 1976 Respiratory Physiology, Edition 3, St Louis, C. V. Mosby.

TESCH PA, LINDBERG S 1984 Blood lactate accumulation during arm exercise in world class kayak paddlers and strength trained athletes. European Journal of Applied Physiology $52: 441-445$ 